\title{
Allelic associations and homozygosity at loci from HLA-B to D6S299 in genetic haemochromatosis
}

\author{
R Raha-Chowdhury, D J Bowen, A K Burnett, M Worwood
}

\begin{abstract}
Haemochromatosis (GH) is an autosomal recessive disorder in which increased iron absorption causes iron overload. The gene (HFE) is closely linked to HLA-A on chromosome 6 (6p21.3) but has not yet been identified. We have examined eight polymorphic loci, HLA-B (most centromeric), I82, D6S265, HLA-A, D6S128, HLA-F, D6S105, and D6S299 (most telomeric) in 37 unrelated patients and 60 control subjects. There are also significant positive associations between $\mathrm{GH}$ and alleles at all loci except D6S299. Analysis of $48 \mathrm{GH}$ chromosomes in which haplotypes could be established showed that the most common haplotype was I82-2:D6S265-1:HLAA3:D6S128-2:HLA-F1:D6S105-8. This was present in 28 of 48 chromosomes. In 14 the haplotype included HLA-B7 but only in seven did this extend beyond the telomere to D6S299-2 (the most common allele on GH chromosomes at this locus). In 36 out of 48 chromosomes the two locus haplotype, F1:D6S105-8 was present. Since haemochromatosis appears to originate from a founder mutation we have examined linkage disequilibrium between these various loci and GH using calculations of $p_{\text {excess. }}$. The maximum value $(0 \cdot 72$, 95\% CI $0.55-0.85$ ) is given by $\mathrm{D6S105-8}$ but is not significantly different from values for HLA-A3 and HLA-F1 $(0.50,95 \%$ CI $0.34-0.61$ and $0.49,0.25-0.66$ respectively). However, both HLA-A and D6S105 give a value for $p_{\text {excess }}$ which is significantly higher than that for the most centromeric marker, HLA-B $(0 \cdot 17,95 \%$ CI $0 \cdot 02-0 \cdot 30)$. We have counted the number of patients who are homozygous for the common allele at each locus. At D6S105, 22 patients are homozygous for allele 8, with 18 homozygous for HLA-F1 and 10 homozygous for A3. The pattern of cumulative homozygosity suggests a gene location closer to D6S105 than HLA-A. We have also analysed our data for divergence from the apparent founder haplotype (A3:F1:105-8) and have calculated the theoretical frequencies of crossovers between loci. These data suggest a location telomeric to D6S105. A more precise localisation of the gene may be possible with the identification of new markers around D6S105.
\end{abstract}

(F Med Genet 1995;32:446-452)
Genetic haemochromatosis (GH) is an autosomal recessive disorder, common in European populations, in which increased iron absorption causes parenchymal iron overload in a variety of tissues. ${ }^{1}$ This eventually leads to the clinical manifestations which include liver cirrhosis, diabetes, hypogonadism, and arthritis. Patients who are depleted of iron by venesection before development of cirrhosis have a normal life expectancy, but cirrhosis is usually irreversible and often leads to hepatocellular carcinoma. ${ }^{2}$ Haemochromatosis is a disorder in which careful family screening is justified in order to identify people who are homozygous for the disease before they develop cirrhosis. However, effective population screening must await the identification of the genetic change which causes haemochromatosis. ${ }^{1}$ Simon et $a l^{3}$ described an association between haemochromatosis and HLA antigens $A 3$ and B14 suggesting that the haemochromatosis gene (HFE) was linked to HLA-A on the short arm of chromosome 6. This association with HLA class I antigens has since been confirmed by many investigators. ${ }^{4}$ Pedigree analysis placed the haemochromatosis gene within $1 \mathrm{cM}$ of HLAA at $6 \mathrm{p} 21.3 .^{5-7}$

In the last few years there has been considerable refinement of the genetic map around HLA-A. Several new class I genes have been identified in the region beyond HLA-A and towards the telomere, for example HLA-H, HLA-G, and HLA-F ${ }^{8}$ Recently it has been shown that the more telomeric marker D6S105 (located at least $1 \mathrm{cM}$ from HLA-A ${ }^{9}$ ) shows a highly significant allelic association with haemochromatosis ${ }^{610}$ and Jazwinska $e t a l^{6}$ have proposed that the HFE gene lies very close to this marker. However, other groups ${ }^{711}$ have found no significant association between alleles at HLA-F and haemochromatosis although HLA-F lies between HLA-A and D6S105.

Here we describe genotyping with probes from the region around HLA-A: I82, D6S265, $\mathrm{H}$, and $\mathrm{F}$ and also with two, more telomeric, microsatellite markers (D6S105, D6S299). We show that alleles of HLA-F, as well as HLA-A and D6S105, are in linkage disequilibrium with HFE. We have been able to establish a common haplotype in haemochromatosis subjects. Our results indicate a gene location closer to D6S105 than HLA-A. 
Table 1 Allele frequencies from HLA-B to D6S299 in normal subjects and in unrelated patients with haemochromatosis

\begin{tabular}{|c|c|c|c|c|c|c|c|}
\hline \multirow[t]{2}{*}{ Locus } & \multirow[t]{2}{*}{ Allele } & \multicolumn{2}{|l|}{ Normal } & \multicolumn{2}{|c|}{ Haemochromatosis } & \multirow[t]{2}{*}{$\chi^{2}$} & \multirow[t]{2}{*}{$p$} \\
\hline & & No & $\%$ & No & $\%$ & & \\
\hline \multirow{3}{*}{$\begin{array}{l}\text { HLA-B† } \\
\text { I82* }\end{array}$} & B7 $\ddagger$ & $16 / 120$ & $13 \cdot 3$ & $18 / 64$ & $28 \cdot 1$ & $5 \cdot 1$ & 0.024 \\
\hline & & $61 / 126$ & $48 \cdot 4$ & $19 / 72$ & $26 \cdot 4$ & $8 \cdot 3$ & $3.9 \times 10^{-3}$ \\
\hline & 2 & $65 / 126$ & $51 \cdot 6$ & $53 / 72$ & $73 \cdot 6$ & $8 \cdot 3$ & $3.9 \times 10^{-3}$ \\
\hline \multirow[t]{6}{*}{ D6S265† } & 15 & $12 / 120$ & $10 \cdot 0$ & $38 / 74$ & $51 \cdot 4$ & $38 \cdot 8$ & $6 \times 10^{-10}$ \\
\hline & 3 & $43 / 120$ & $35 \cdot 8$ & $13 / 74$ & $17 \cdot 6$ & $6 \cdot 6$ & 0.01 \\
\hline & 4 & $6 / 120$ & $5 \cdot 0$ & $9 / 74$ & $12 \cdot 2$ & - & - \\
\hline & 5 & $38 / 120$ & $31 \cdot 7$ & $12 / 74$ & $16 \cdot 2$ & $4 \cdot 9$ & 0.03 \\
\hline & 6 & $19 / 120$ & $15 \cdot 8$ & $2 / 74$ & $2 \cdot 7$ & $6 \cdot 8$ & 0.009 \\
\hline & 7 & $2 / 120$ & 1.7 & $0 / 74$ & 0.0 & - & - \\
\hline \multirow{4}{*}{$\begin{array}{l}\text { HLA-A } \\
\text { D6S128* }\end{array}$} & A3‡ & $14 / 120$ & $11 \cdot 7$ & $41 / 74$ & $55 \cdot 4$ & $35 \cdot 1$ & $3 \times 10^{-9}$ \\
\hline & $1+2 \|$ & $27 / 68$ & $39 \cdot 7$ & $48 / 72$ & $66 \cdot 7$ & $9 \cdot 2$ & $2.5 \times 10^{-3}$ \\
\hline & & $39 / 68$ & $57 \cdot 4$ & $23 / 72$ & 31.9 & $8 \cdot 2$ & $4.3 \times 10^{-3}$ \\
\hline & 4 & $2 / 68$ & 2.9 & $1 / 72$ & $1 \cdot 4$ & - & - \\
\hline \multirow[t]{3}{*}{ HLA-F† } & 1 & $47 / 110$ & $42 \cdot 7$ & $51 / 72$ & $70 \cdot 8$ & $12 \cdot 7$ & $3.6 \times 10^{-4}$ \\
\hline & 2 & $16 / 110$ & 14.5 & $9 / 72$ & 12.5 & & \\
\hline & 3 & $47 / 110$ & $42 \cdot 7$ & $12 / 72$ & $16 \cdot 7$ & $12 \cdot 3$ & $4.5 \times 10^{-4}$ \\
\hline \multirow[t]{6}{*}{ D6S105† } & 39 & $4 / 116$ & $3 \cdot 4$ & $1 / 74$ & $1 \cdot 4$ & - & - \\
\hline & 4 & $5 / 116$ & $4 \cdot 3$ & $5 / 74$ & 6.8 & - & - \\
\hline & 5 & $17 / 116$ & $4 \cdot 3$ & $5 / 74$ & $6 \cdot 8$ & - & - \\
\hline & 6 & $41 / 116$ & $35 \cdot 3$ & $7 / 74$ & $9 \cdot 5$ & $14 \cdot 7$ & $1.3 \times 10^{-4}$ \\
\hline & 7 & $10 / 116$ & $8 \cdot 6$ & $1 / 74$ & 1.4 & $3 \cdot 1$ & 0.076 \\
\hline & 8 & $33 / 116$ & $28 \cdot 4$ & $59 / 74$ & $78 \cdot 4$ & $43 \cdot 2$ & $1.3 \times 10^{-10}$ \\
\hline \multirow[t]{7}{*}{ D6S299† } & 1 & $15 / 114$ & $13 \cdot 2$ & $15 / 68$ & $22 \cdot 1$ & - & - \\
\hline & 2 & $36 / 114$ & $31 \cdot \overline{6}$ & $18 / 68$ & 26.5 & - & - \\
\hline & 3 & $14 / 114$ & $12 \cdot 3$ & $14 / 68$ & $20 \cdot 6$ & - & - \\
\hline & 4 & $14 / 114$ & $12 \cdot 3$ & $5 / 58$ & $7 \cdot 3$ & - & - \\
\hline & 5 & $23 / 114$ & $20 \cdot 2$ & $7 / 68$ & $10 \cdot 3$ & - & - \\
\hline & 6 & $8 / 114$ & $7 \cdot 0$ & $7 / 68$ & $10 \cdot 3$ & - & - \\
\hline & 7 & $4 / 114$ & 3.5 & $2 / 68$ & $2 \cdot 9$ & - & - \\
\hline
\end{tabular}

* Control group 1.

† Control group 2, HLA-B, HLA-A, and HLA-F were also analysed in group 1.

$¥$ Only the most common antigen found in patients has been included.

Alleles ${ }^{18}$ increase by 2 bp from allele $1=124$ bp. Allele 2 has not been observed.

Alleles $1+2$ referred to as " 2 " in text.

I Alleles decrease by 2 bp from allele $1=138$ bp. Alleles 1, 2, 9-12 not included (not represented in the patient group).

\section{Materials and methods}

PATIENTS AND CONTROL SUBJECTS

In order to study the association of haemochromatosis with alleles at various loci we have studied 37 unrelated patients with haemochromatosis and the controls described below. Chromosomes carrying haemochromatosis were identified in 20 families from south Wales and south west Scotland.

The diagnosis of HFE was made by standard methods ${ }^{12}$ including a consistently raised transferrin saturation ( $>60 \%$ ) and a serum ferritin concentration exceeding $300 \mu \mathrm{g} / 1$ in males and $200 \mu \mathrm{g} / 1$ in females. The diagnosis was confirmed by venesection with removal of at least $5 \mathrm{~g}$ of iron before iron depletion. In most cases a liver biopsy was performed and iron overload shown. HLA-A and HLA-B typing were performed with the standard NIH technique ${ }^{13}$ at the Welsh Regional Blood Transfusion Service. There were two groups of control subjects. The first group of controls $(\max n o=62)$ were blood donors from the Welsh Regional Blood Transfusion Service and were used to examine associations between alleles at various class I genes. The second group $(n=60)$ were from the Welsh Regional Blood Transfusion Service Unrelated Bone Marrow Donor Register and were between 18 and 45 years old. They were consecutive subjects screened for haemochromatosis. ${ }^{14}$ None showed abnormalities in serum iron or ferritin concentration. These samples were analysed for D6S265, D6S105, D6S299, and HLA-F as well as being HLA typed.

\section{SOUTHERN BLOTTING}

DNA was prepared from peripheral blood by the method of Miller et al. ${ }^{15}$ DNA $(8 \mu \mathrm{g})$ was digested with various restriction endonucleases as recommended by the suppliers (NBL Gene Sciences, Cramlington, Northumberland, UK). Electrophoresis was carried out in $0.8 \%$ agarose gels. Southern blotting was performed with nylon membranes (PALL Biotype B transfer membrane, Pall Europe, Portsmouth, England) by capillary transfer. Probes were labelled with the random oligonucleotide primer method in the presence of $\left[\alpha-{ }^{32} \mathrm{P}\right]$ dCTP using the Boehringer kit. Radioactivity was detected by autoradiography with ortho-G film (Kodak) using intensifying screens. The filters were then stripped by heating in $0.5 \%$ SDS at $85^{\circ} \mathrm{C}$ before rehybridisation. Approximate fragment sizes were estimated by comparison with markers of lambda DNA digested with HindIII and $E c o$ RI. Probe I82 is a $4.4 \mathrm{~kb} P s t \mathrm{I}$ fragment located $100 \mathrm{~kb}$ centromeric to HLA-A. This gives a biallelic pattern ( 15 and $7 \cdot 4 \mathrm{~kb}$ ) when DNA is digested with $B g I I I .{ }^{16}$ Probe pMC 6.7 is a $700 \mathrm{bp} E c o R I$ fragment located $20 \mathrm{~kb} \mathrm{5'}$ of HLA-H. ${ }^{17}$ This gives a four allele RFLP with TaqI $(11.0,10.5,8.0,2.0 \mathrm{~kb})$ but we have combined alleles 1 and 2 which are sometimes difficult to separate on agarose gels (table 1). Probe HLA-F (5UT) was derived from the full length genomic clone Dew $3^{19}$ by digestion with SstI and HindIII to give a $700 \mathrm{bp}$ fragment. This is the probe F5UT referred to by Gruen et al. ${ }^{20}$ This probe identifies a three allele RFLP $(2 \cdot 0,1 \cdot 85,1 \cdot 4 \mathrm{~kb})$ with $X b a \mathrm{I}^{21}$

\section{MICROSATELLITE ANALYSIS}

The microsatellites amplified were the dinucleotide repeats D6S105, ${ }^{22}$ D6S265, ${ }^{23}$ D6S299, ${ }^{23}$ and D6S202 (pHZ-30/2.6) ${ }^{24}$ The latter is located ${ }^{25}$ at $6 \mathrm{p} 23$ and results are only given to confirm a recombination involving 


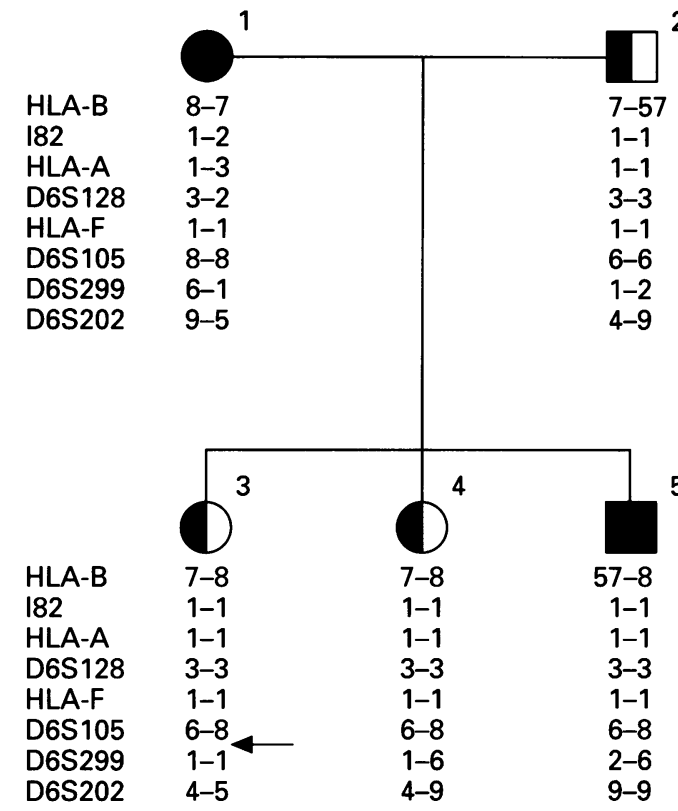

\section{Homozygous for $\mathrm{GH}$ \\ $\square$ Heterozygous for $\mathrm{GH}$}

Figure 1 Pedigree showing a recombination involving D6S299.

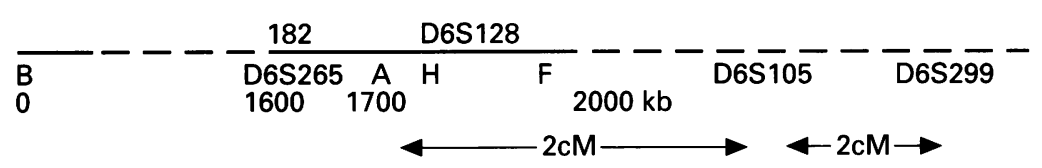

Figure 2 Location of the loci examined at chromosome $6 p 21.3$ and towards the telomere. The distance in $\mathrm{kb}$ from $H L A-B$ to $H L A-F$ is that given by Adberrahim et al ${ }^{29}{ }^{2} 82^{30}$ and D6S265 $5^{31}$ are approximately $100 \mathrm{~kb}$ centromeric to $H L A-A$. D6S128 $8^{32}$ is located $20 \mathrm{~kb}$ telomeric to $H L A-H$ (approximately $100 \mathrm{~kb}$ towards the telomere from $H L A-A$ ) and is outside the deleted region, including $H L A-H$, in chromosomes carrying $H L A-A 23$ or A24. Approximate genetic locations are given from D6S105 and D6S299. ${ }^{23}$ D6S105 has been shown to be telomeric to HLA-A by in situ hybridisation. ${ }^{9}$

No of subjects homozygous for the given allele at each locus

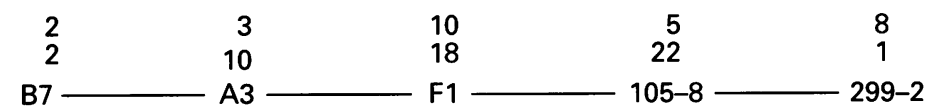

Cumulative homozygosity: No of subjects homozygous for all loci starting at D6S105 (top) or HLA-A3 (bottom)

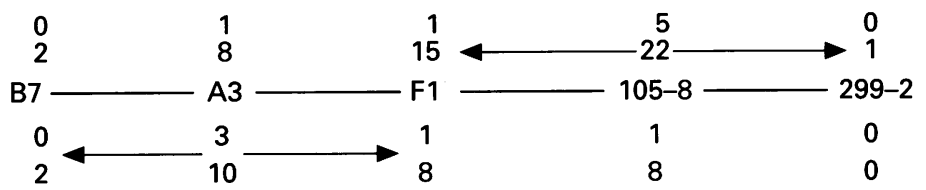

Figure 3 Homozygosity at the various alleles in related patients with haemochromatosis and controls. Above the genetic map the number of patients homozygous for the most common allele in patients is given. For patients $n=37$ and for controls $n=55$. The control group was group 2 (see Materials and methods) as well as three subjects from the haemochromatosis family study who did not carry haemochromatosis genes. In some cases haemochromatosis family study who did not carry haemochromatosis genes. In some cases cumulative homozygosity is given. Starting with D6S105 (homozygosity for allele 8) the number of patients or controls homozygous at each successive locus is given both towards HLA-B and for D6S105 and D6S299. Below that cumulative homozygosity is given starting with homozygosity for $H L A-A 3$.
2 D6S299 (fig 1). The reaction mixture of $50 \mu \mathrm{l}$ volume contained $500 \mathrm{ng}$ DNA with primers at a final concentration of $1 \mu \mathrm{mol} / 1,200 \mu \mathrm{mol} / 1$ dNTPs, $1.5 \mathrm{mmol} / 1 \mathrm{MgCl}_{2}$ and $1 \mathrm{U}$ of $T a q$ polymerase (Bioline UK). The "CA" primers were labelled with $\left[\alpha{ }^{32} \mathrm{P}\right]$ ATP using T4 polynucleotide kinase (NBL). Samples were overlaid with mineral oil and taken through 27 cycles at $94^{\circ} \mathrm{C}$ for 30 seconds, $55^{\circ} \mathrm{C}$ for 30 seconds, and $72^{\circ}$ for one minute in a Perkin Elmer Cetus DNA Thermal Cycler. The last extension step was for 10 minutes. A different programme was used for D6S299: $94^{\circ} / 30$ seconds, $52 \% / 30$ seconds, $72 \% 60$ seconds for 25 cycles followed by 10 cycles at $48^{\circ}$ instead of $52^{\circ}$.

PCR products were denatured and analysed in polyacrylamide gels under denaturing conions $(6 \%$ polyacrylamide containing $6.7 \mathrm{~mol} / 1$ urea gel size $400 \times 330 \times 0.4 \mathrm{~mm}$ ) and bands were detected by autoradiography. Nominal allele sizes were determined by comparison with the migration of pBR322 DNA cut with MspI (New England Biolabs, Hitchin, UK). Sizes were confirmed by sequencing and counting the number of repeats ${ }^{10}$ in the cases of D6S105, D6S299, and D6S202. Allele numbers and sizes are given in table 1 except for D6S202 for which there were 12 alleles with the largest being $154 \mathrm{bp}$.

\section{STATISTICAL ANALYSIS}

Allele frequencies were determined by inspection and people possessing a single allele were assumed to be homozygous for that allele. The significance of differences between frequencies for patients and controls was determined with the $\chi^{2}$ test (with Yates's correction). Two locus linkage disequilibrium values and corrected values were calculated as described by Lewontin. ${ }^{26}$ The $\mathrm{p}_{\text {excess }}$ values ${ }^{27}$ and $95 \%$ confidence limits were calculated as described by Armitage and Berry ${ }^{28}$ ( $\mathrm{p}_{\text {excess }}$ is the same as "aetiological fraction" or "attributable risk").

\section{Results}

\section{P ALLELE FREQUENCIES}

The location of the loci examined is given in fig 2. Table 1 gives allele frequencies in both unrelated patients with haemochromatosis and

Table 2 Two locus haplotypest (HLA-A/other) in controls showing significant, positive $D^{\prime}$ values (uncorrected $p<0.05$ )

\begin{tabular}{|c|c|c|c|c|}
\hline \multirow[b]{2}{*}{ Haplotype } & \multicolumn{2}{|c|}{ Controls } & \multirow[b]{2}{*}{$x^{2}$} & \multirow[b]{2}{*}{$p S$} \\
\hline & No & $D^{\prime}$ value & & \\
\hline A2-I82-2 & $62 \ddagger$ & $0 \cdot 66$ & $4 \cdot 0$ & $*$ \\
\hline A3-D6S128-2 & $33 \neq$ & 0.96 & $9 \cdot 8$ & $* *$ \\
\hline A1-F1 & $100 \|$ & 0.53 & $4 \cdot 1$ & $*$ \\
\hline A3-F1 & 100 & 0.67 & $4 \cdot 5$ & $*$ \\
\hline A2-F3 & 100 & $0 \cdot 70$ & 6.5 & $*$ \\
\hline A11-F2 & 100 & 0.62 & $10 \cdot 6$ & $* *$ \\
\hline A28-F2 & 100 & 0.49 & $9 \cdot 1$ & $* *$ \\
\hline Al-D6S105-8 & 57 拉 & 0.47 & $12 \cdot 7$ & $* * *$ \\
\hline
\end{tabular}

+ Alleles at D6S265 are highly correlated with HLA-A alleles. ${ }^{18}$ $¥$ Control group 1 , 㧊 control group 2 .

Significance of $\mathrm{D}^{\prime}$ value.

${ }_{*}^{*} \mathrm{p}<0.05,{ }^{* *} \mathrm{p}<0.01,{ }^{* * *} \mathrm{p}<0.001$

$\|$ All available control subjects from both groups with results for the two loci were included. 
Table 3 Haplotypes in patients with haemochromatosis. Haplotypes were derived by an analysis of pedigrees except for patients 50, 62, and 64 who were homozygous for alleles at all loci from I82 to D6S105. *indicates the "common" allele shown in ( ) next to the markers. ${ }^{+}$indicates that the alleles for D6S299 could not be assigned to haplotypes. \#indicates that HLA-A or B typing was carried out by genotyping in the family and corresponding antigens cannot always be assigned.

\begin{tabular}{|c|c|c|c|c|c|c|c|c|c|c|}
\hline \multirow[b]{3}{*}{$\begin{array}{l}\text { HLA-B (7) } \\
\text { I82 (2) } \\
\text { D6S265 (1) } \\
\text { HLA-A (3) } \\
\text { D6S128 (2) } \\
\text { HLA-F (1) } \\
\text { D6S105 (8) } \\
\text { D6S299 (2) } \\
\end{array}$} & \multicolumn{10}{|c|}{ Patient No. } \\
\hline & \multicolumn{2}{|l|}{01} & \multicolumn{2}{|l|}{48} & \multicolumn{2}{|l|}{06} & \multicolumn{2}{|l|}{12} & \multicolumn{2}{|l|}{54} \\
\hline & $\begin{array}{r}08 \\
1 \\
3 \\
01 \\
3 \\
* \\
* \\
6\end{array}$ & $\begin{array}{l}* \\
* \\
* \\
* \\
* \\
* \\
* \\
1\end{array}$ & $\begin{array}{l}* \\
* \\
* \\
* \\
* \\
* \\
* \\
*\end{array}$ & $\begin{array}{l}* \\
* \\
* \\
* \\
* \\
* \\
* \\
1\end{array}$ & $\begin{array}{r}62 \\
2 \\
5 \\
02 \\
3 \\
3 \\
6\end{array}$ & $\begin{array}{l}* \\
* \\
* \\
* \\
* \\
* \\
*\end{array}$ & $\begin{array}{r}44 \\
2 \\
5 \\
02 \\
2 \\
3 \\
3 \\
7\end{array}$ & $\begin{array}{l}* \\
* \\
* \\
* \\
* \\
* \\
* \\
4\end{array}$ & $\begin{array}{l}* \\
* \\
* \\
* \\
* \\
* \\
* \\
*\end{array}$ & $\begin{array}{l}* \\
* \\
* \\
* \\
* \\
* \\
*\end{array}$ \\
\hline & \multicolumn{10}{|c|}{ Patient No } \\
\hline & 18 & & 24 & & 65 & & 25 & & 69 & \\
\hline $\begin{array}{l}\text { HLA-B } \\
\text { I82 } \\
\text { D6S265 } \\
\text { HLA-A } \\
\text { D6S128 } \\
\text { HLA-F } \\
\text { D6S105 } \\
\text { D6S299 }\end{array}$ & $\begin{array}{r}44 \\
2 \\
4 \\
11 \\
3 \\
* \\
* \\
3\end{array}$ & $\begin{array}{r}55 \\
2 \\
5 \\
2 \\
2 \\
3 \\
* \\
*\end{array}$ & $\begin{array}{r}44 \\
1 \\
5 \\
29 \\
2 \\
3 \\
* \\
*\end{array}$ & $\begin{array}{r}44 \\
1 \\
5 \\
28 \\
3 \\
2 \\
8 \\
3\end{array}$ & $\begin{array}{r}08 \\
1 \\
3 \\
01 \\
3 \\
* \\
*\end{array}$ & $\begin{array}{c}44 \\
* \\
* \\
* \\
* \\
* \\
*\end{array}$ & $\begin{array}{r}41 \\
1 \\
3 \\
01 \\
3 \\
* \\
* \\
1\end{array}$ & $\begin{array}{r}62 \\
2 \\
5 \\
25 \\
2 \\
3 \\
6 \\
2\end{array}$ & $\begin{array}{r}44 \\
2 \\
4 \\
11 \\
3 \\
2 \\
* \\
*\end{array}$ & $\begin{array}{l}* \\
* \\
* \\
* \\
* \\
* \\
* \\
*\end{array}$ \\
\hline \multirow{2}{*}{ D6S299 } & \multicolumn{10}{|c|}{ Patient No } \\
\hline & 57 & & 45 & & 41 & & 43 & & 94 & \\
\hline $\begin{array}{l}\text { HLA-B } \\
\text { I82 } \\
\text { D6S265 } \\
\text { HLA-A } \\
\text { D6S128 } \\
\text { HLA-F } \\
\text { D6S105 } \\
\text { D6S299 }\end{array}$ & $\begin{array}{l}51 \\
* \\
* \\
* \\
* \\
* \\
* \\
*\end{array}$ & $\begin{array}{r}13 \\
2 \\
5 \\
02 \\
3 \\
3 \\
6 \\
3\end{array}$ & $\begin{array}{r}14 \\
* \\
* \\
* \\
* \\
* \\
* \\
4\end{array}$ & $\begin{array}{c}44 \\
* \\
* \\
* \\
* \\
* \\
* \\
*\end{array}$ & $\begin{array}{l}* \\
* \\
* \\
* \\
* \\
* \\
* \\
4\end{array}$ & $\begin{array}{r}44 \\
2 \\
5 \\
02 \\
3 \\
3 \\
6 \\
3\end{array}$ & $\begin{array}{r}\# \\
1 \\
5 \\
31 \\
4 \\
* \\
* \\
1\end{array}$ & $\begin{array}{l}* \\
* \\
* \\
* \\
* \\
* \\
* \\
7\end{array}$ & $\begin{array}{l}* \\
* \\
* \\
* \\
* \\
* \\
* \\
3\end{array}$ & $\begin{array}{l}\# \\
1 \\
6 \\
\# \\
3 \\
3 \\
4 \\
2\end{array}$ \\
\hline \multirow{2}{*}{ D6S299 } & \multicolumn{10}{|c|}{ Patient No } \\
\hline & 98 & & 39 & & 33 & & 56 & & 52 & \\
\hline $\begin{array}{l}\text { HLA-B } \\
\text { I82 } \\
\text { D6S265 } \\
\text { HLA-A } \\
\text { D6S128 } \\
\text { HLA-F } \\
\text { D6S105 } \\
\text { D6S299 }\end{array}$ & $\begin{array}{l}\# \\
* \\
* \\
* \\
* \\
* \\
* \\
5\end{array}$ & $\begin{array}{l}* \\
* \\
* \\
* \\
* \\
* \\
* \\
3\end{array}$ & $\begin{array}{r}62 \\
* \\
* \\
* \\
* \\
* \\
* \\
5\end{array}$ & $\begin{array}{r}07 \\
* \\
* \\
* \\
* \\
* \\
* \\
5\end{array}$ & $\begin{array}{r}08 \\
1 \\
3 \\
01 \\
3 \\
* \\
* \\
*\end{array}$ & $\begin{array}{l}* \\
* \\
* \\
* \\
* \\
* \\
* \\
6\end{array}$ & $\begin{array}{r}55 \\
2 \\
4 \\
11 \\
3 \\
2 \\
8 \\
4\end{array}$ & $\begin{array}{l}* \\
* \\
* \\
* \\
* \\
* \\
* \\
*\end{array}$ & $\begin{array}{l}* \\
* \\
* \\
* \\
* \\
* \\
*\end{array}$ & $\begin{array}{r}35 \\
1 \\
3 \\
03 \\
2 \\
1 \\
6\end{array}$ \\
\hline \multirow{2}{*}{ D6S299 } & \multicolumn{10}{|c|}{ Patient No } \\
\hline & 50 & & 62 & & 64 & & 63 & & & \\
\hline $\begin{array}{l}\text { HLA-B } \\
\text { I82 } \\
\text { D6S265 } \\
\text { HLA-A } \\
\text { D6S128 } \\
\text { HLA-F } \\
\text { D6S105 } \\
\text { D6S299 }\end{array}$ & $\begin{array}{r}15 \\
* \\
* \\
* \\
* \\
* \\
*\end{array}$ & $\begin{array}{c}40 \\
* \\
* \\
* \\
* \\
* \\
*\end{array}$ & $\begin{array}{c}14 \\
* \\
* \\
* \\
* \\
* \\
* \\
1\end{array}$ & $\begin{array}{c}05 \\
* \\
* \\
* \\
* \\
* \\
* \\
2^{+}\end{array}$ & $\begin{array}{l}* \\
* \\
* \\
* \\
* \\
* \\
* \\
2\end{array}$ & $\begin{array}{l}14 \\
* \\
* \\
* \\
* \\
* \\
* \\
5^{+}\end{array}$ & $\begin{array}{r}08 \\
1 \\
3 \\
01 \\
3 \\
* \\
*\end{array}$ & $\begin{array}{r}22 \\
1 \\
3 \\
01 \\
3 \\
* \\
*\end{array}$ & & \\
\hline
\end{tabular}

control subjects. In controls, alleles at HLA-A and $B$ show significant, positive linkage disequilibrium (data not shown), with the A1-B8 haplotype common in European populations being most frequent. There are also significant associations between alleles at the other loci studied here except for D6S299. Examples are given in table 2 as two locus haplotypes involving HLA-A. We have not included D6S265 alleles which are strongly associated with alleles of HLA-A. ${ }^{18}$ In controls D6S1058 is in linkage disequilibrium with HLA-A1. This association is actually with the Al-B8 haplotype. ${ }^{18}$ In contrast to all the other loci examined we have found a recombination involving D6S299 in one family (fig 2). In terms of allelic association with GH (table 1) we first studied loci close to HLA-A which have been placed on the physical map of the region (fig 1 ). I-82 allele 2, D6S265-1, HLA-A3, D6S128-2, HLA-F1 were all significantly more frequent in haemochromatosis than in controls. The search for allelic associations were extended to flanking markers HLA-B, D6S105, and D6S299. As expected HLA-B7 was significantly increased in haemochromatosis ${ }^{5}$ and D6S105-8 was strongly associated with the disorder. ${ }^{610}$ However, D6S299 showed no allelic association with $\mathrm{GH}$.

\section{HAPLOTYPES IN HAEMOCHROMATOSIS}

An examination of haplotypes in 24 unrelated patients (table 3 ) showed a common haplotype extending from HLA-B to D6S105. This haplotype is B7:I82-2:D6S265-1:A3:D6S1282:F1:D6S105-8 and from I82 to D6S105-8 was present in 28 out of 48 chromosomes. In 14 of these the haplotype included HLA-B7. In only seven chromosomes did the haplotype extend towards the telomere to D6S299-2 (the most common allele on haemochromatosis chromosomes at this locus). In 36 of 48 chromosomes the two locus haplotype, F1:D6S1058 , was present. $\mathrm{GH}$ is a recessive disorder and homozygosity for the common haplotype should also be common. Homozygosity for the most common alleles in haemochromatosis is shown in fig 3 and compared with controls. Almost $60 \%$ of patients (22/ 37) were homozygous for D6S105-8 and the number homozygous at other loci declines steadily to $18 / 37(49 \%)$ at HLA-F, 10/37 (28\%) at HLA-A, and $2 / 37(5 \%)$ at HLA-B. Only one patient (out of 34 tested) was homozygous for D6S299 allele 2. For cumulative homozygosity, running from D6S105 to HLA-B, the $\%$ declines beyond HLA-F: $59 \%$ of patients are homozygous for D6S105-8, 41\% are also homozygous for $\mathrm{F} 1$, but only $22 \%$ are also homozygous for HLA-A3. Of five controls homozygous for D6S105-8 only one was homozygous for both F1 and D6S105-8. However, starting with $\mathrm{A} 3$ the number of patients homozygous for the common alleles at HLA-F and D6S105 remains relatively constant up to D6S105.

WHICH IS THE CLOSEST MARKER TO THE HAEMOCHROMATOSIS GENE?

The evidence presented here and earlier ${ }^{510}$ strongly suggests that haemochromatosis appears to originate from a founder mutation

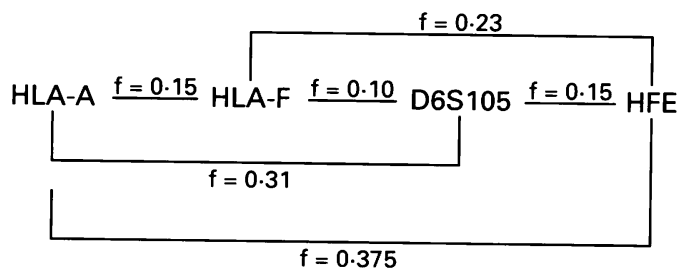

Figure 4 Crossover frequencies in haemochromatosis. These have been calculated assuming a founder haplotype HLA-A3:F1:D6S105-8 (see text). 
Table 4 Linkage disequilibrium between haemochromatosis and the various markers

\begin{tabular}{llll}
\hline Locus and allele & No patients/No controls & $p_{\text {excess }}{ }^{*}$ & $95 \%$ CI \\
\hline HLA-B7 & $32 / 60$ & $0 \cdot 17$ & $0 \cdot 02-0 \cdot 30$ \\
I82-2 & $36 / 63$ & $0 \cdot 46$ & $0 \cdot 17-0 \cdot 64$ \\
D6S265-1 & $37 / 60$ & $0 \cdot 46$ & $0 \cdot 31-0 \cdot 58$ \\
HLA-A3 & $37 / 60$ & 0.50 & $0 \cdot 34-0 \cdot 61$ \\
D6S128-2 & $36 / 34$ & $0 \cdot 45$ & $0 \cdot 19-0 \cdot 62$ \\
HLA-F1 & $36 / 55$ & $0 \cdot 49$ & $0 \cdot 25-0 \cdot 66$ \\
D6S105-8 & $37 / 58$ & $0 \cdot 72$ & $0 \cdot 55-0.82$ \\
D6S299† & $34 / 57$ & - & \\
\hline
\end{tabular}

* See Materials and methods.

† No allele significantly more common in haemochromatosis.

which has multiplied in the population through successive generations. In this situation traditional methods for assessing linkage disequilibrium may not be appropriate for markers which are close to the disease gene and which vary in both the number of alleles and the allele frequency in the control population. For this reason the approach described by Hastbacka et $a l^{27}$ was adopted by calculating $\mathrm{p}_{\text {excess }}$ for all the loci examined. The value of $p_{\text {excess }}$ is low for HLA-B and D6S299 which are located either side of the probable location of the HFE gene. Loci around HLA-A (I82, D6S265, D6S128, and HLA-F) show intermediate values but the highest value is found for D6S105 (table 4). However, examination of confidence limits (table 4) shows that although HLA-A and D6S105 show significantly higher values for $p_{\text {excess }}$ than HLA-B they do not differ significantly from each other or from that for HLA-F.

\section{Discussion}

Despite the clear demonstration that the gene for haemochromatosis lies within $1 \mathrm{cM}$ of HLA- $\mathrm{A}^{5}$ it has not been identified and there has been little further definition of its map position. It is now known that the gene density in the region including $1 \mathrm{Mb}$ of DNA around HLA-A is as high as one expressed gene or pseudogene per $20 \mathrm{~kb} .{ }^{33} \mathrm{~A}$ number of studies of polymorphic loci around HLA-A have been reported. Boretto et $a l^{30}$ examined anonymous markers centromeric to HLA-A and found a strong association between the $7 \cdot 4 \mathrm{~kb}$ allele of I82 (BgIII) and haemochromatosis. Our results for I82 are very similar. More centromeric markers showed no significant associations. Gasparini et $a l^{7}$ carried out a linkage analysis with markers DQ $\alpha$, HLA-B, I82, HLA-A, HLA-F, D6S105, D6S109, and D6S89 and concluded that the gene for $\mathrm{GH}$ was close to I82. Although HLA-F was included (PCR amplification of a $3^{\prime}$ dinucleotide repeat) it was found to be located at a recombination frequency of 0.027 from HLA-A and D6S105 appeared to be at a recombination frequency of 0.058 from HLA-A. Yaouang et al ${ }^{11}$ carried out a haplotype analysis with markers from P3A (centromeric to HLA-B) to HLA-F. They established a frequent haplotype on haemochromatosis chromosomes: I82-2:A3:p6.7-1. P6.7 is a probe from a locus close to HLA-H and is referred to as D6S128 in the present paper. The HLA-F polymorphism studied was not informative: the two allele polymorphism shown with HindIII had a frequency of $93 \%$ at allele 1 for both normal and haemochromatosis chromosomes. HLA-F alleles thus showed no association with haemochromatosis. Again this supports a gene location close to HLA as suggested by Gasparini et $a l^{7}$ and El Kahloun et al. ${ }^{34}$

Our study confirms the strong associations found for alleles at I82, HLA-A, and D6S128 by Yaouanq et $a l,{ }^{11}$ as all patients but one with HLA-A3 also carried I82-2 and D6S128-2. However, the I82:HLA-A:p6.7 haplotype ${ }^{11}$ is an HLA-A3 (HLA-A*0301) haplotype rather than a haemochromatosis specific haplotype. ${ }^{35}$ This haplotype is also defined by D6S265-1 ${ }^{35}$ and in the following discussion HLA-A 3 will be defined as equivalent to HLA-A*0301 and D6S265-1. Only on one chromosome (fig 2, patient 52) is HLA-A3 not found with D6S2651.

We show that HLA-F is also in the region of strong linkage disequilibrium with HFE. We have confirmed this by applying a PCR which amplifies part of the $5^{\prime}$ untranslated region of the HLA-F gene including an extensive, polypurine tract comprising multiple repeats of tri- and hexanucleotide motifs. ${ }^{36}$ This provides a highly informative genetic marker. Allele 10 is significantly more frequent in patients than controls $\left(\chi^{2}=19 \cdot 7, p=10^{-5}\right.$; Raha-Chowdhury et $a l$, in preparation). The present study also confirms that D6S105-8 is strongly associated with haemochromatosis. ${ }^{610}$ D6S105 is approximately $2 \mathrm{cM}$ telomeric to HLA-A, ${ }^{925}$ but it has not yet been placed on a physical map including HLA-A or HLA-F. Jazwinska et $a l^{6}$ found that D6S105-8 was more strongly associated with haemochromatosis than HLAA3 (relative risk $48.4,95 \%$ CI $18-130$, compared to RR $4 \cdot 8,95 \%$ CI $2 \cdot 4-9 \cdot 3$ ) and proposed that the gene lies very close to D6S105. However, with a similar analysis of relative risk we were not able to distinguish between D6S105-8 and HLA-A3 (RR 13.0, 4.4-30 and $9 \cdot 1,4 \cdot 0-21)$. D6S299 has been placed approximately $4 \mathrm{cM}$ from HLA-A towards the telomere. ${ }^{23}$ We have observed no recombinations involving the markers examined here except for D6S299 (fig 1).

Homozygosity for the alleles most commonly associated with $\mathrm{GH}$ at each locus declines from D6S105 to HLA-F and HLA-A. However, starting from HLA-A the homozygosity rate remains constant as far as D6S105. The former is to be expected as one moves from markers close to the gene to markers further away from the gene, while the latter is to be expected as one moves from a marker remote from the gene to markers which are physically closer to the gene. Towards the telomere, D6S299 (approximately $4 \mathrm{cM}$ from HLA-A) is not included in this region of homozygosity. Thus, from this study, the HFE gene is likely to be centromeric to D6S299. In 1987 Simon et $a l^{5}$ defined the ancestral haplotype for $\mathrm{GH}$ (in which the first mutation occurred) as B7-A3-HFE. We have shown the haplotype D6S265-1, HLA$\mathrm{A}^{*} 0301$, HFE, D6S105-8 is more common and may define the ancestral haplotype more precisely. Our present results confirm the existence of this haplotype. The haplotype F1: 
D6S105-8 (36 out of 48 chromosomes) is more common in haemochromatosis than A3:F1 (28/48) which is also more common than B7A3 (17/48). This may indicate a location for the gene which is telomeric to HLA-F. Examination of linkage disequilibrium for alleles at the various loci examined supports this analysis. Methods of assessing the strength of association between alleles at various loci and HFE have included calculation of relative risk, or odds ratio ${ }^{610}$ and Yule's association coefficient. ${ }^{30}$ However, relative risk depends on the frequency of the allele in the control population and confidence limits for Yule's association coefficient were not given. By taking advantage of a founder effect in the relatively stable Finnish population Hasbacka $e t a l^{27}$ have identified the gene causing diastrophic dysplasia on chromosome 5q. They developed a method of fine structure linkage disequilibrium mapping in which examination of markers located within a $180 \mathrm{~kb}$ stretch of DNA suggested that the gene causing diastrophic dysplasia should lie within $64 \mathrm{~kb}$ of the marker CSFIR (colony stimulating factor 1 receptor). Examination of expressed genes in this region led to the identification of the disease gene.

If haemochromatosis has spread by multiplication of a founder mutation through successive generations then a similar analysis may be valuable in locating the gene. Using the calculation of $p_{\text {excess }}$ the highest value is for D6S105 suggesting a gene location closest to this locus. However the maximum value of $\mathrm{p}_{\text {excess }}$ for D6S105-allele 8 of 0.72 suggests that this marker is still some distance from the HFE gene and additional, closer markers need to be identified. Alternatively, this value of $p_{\text {excess }}$ may indicate that $72 \%$ of HFE chromosomes now carry the ancestral haplotype.

Haplotype data for haemochromatosis patients (table 3 ) were used to assess the possible relative position of HFE to HLA-A, HLA$\mathrm{F}$, and D6S105. These loci may lie in the order A-HFE-F-105, or A-F-HFE-105, or A-F-105HFE. These three possible "maps" predict different probabilities for crossover events between two loci. For example, the probability of crossover occurring between HLA-A and HFE is lowest in the first map and highest in the third map, since in the former they are adjacent while in the latter there is more intervening DNA.

Since haemochromatosis appears to originate from a founder mutation which has multiplied in the population through successive generations, we may detect crossover évents between loci by examination of haplotypes in the patient population to assess their divergence from the ancestral haplotype. The latter appears to be A3:F1:105-8; therefore the appearance of any other allele at HLA-A, HLA$\mathrm{F}$, and D6S105 in either of a patient's two haplotypes may be assumed to reflect a crossover event (in the case of the D6S105 VNTR this assumption is only partly correct since variability may also arise by errors in DNA replication). The frequency of such crossover events will increase as the physical distance between genetic loci increases. Analysis of our data from the paired loci A3-HFE, A3-105(8), A3-F1, F1-HFE, F1-105(8), and HFE-105(8) (where the marker for HFE is the disease state itself) shows the theoretical frequencies of crossovers between loci given in fig 4 . These data suggest the genetic order A-F-D6S105HFE. This analysis is based on a small population of 48 haplotypes, of which 40 were deduced by pedigree analysis and eight by homozygosity for each of the loci between I82 and D6S105. However, this genetic map is consistent with other observations: firstly, A3$\mathrm{F} 1$ is the most common allelic combination in HFE haplotypes; however, where A3 is replaced by $\mathrm{A} 11$ it is usually accompanied by $\mathrm{F} 2$. The allelic combination A11-F2 is common in the normal population, suggesting that crossover occurring between HFE and HLA-F results in the bulk replacement of A11-F2 for A3$\mathrm{F} 1$. Secondly, in the above pairwise analyses we observed that a change at D6S105 was generally accompanied by a concomitant replacement at HLA-A while in comparison replacements at HLA-A frequently occurred without change at D6S105. Thirdly, this crossover analysis did not assume any initial map but nevertheless resulted in the correct relative placement of HLA-A, HLA-F, and D6S105.

Although it has been known since 1975 that the gene causing $\mathrm{GH}$ lies close to the HLA-A gene $^{3}$ on chromosome $6 p$ there has been little further progress in locating it. Neither informative chromosome deletions or translocations nor informative recombinations involving disease chromosomes have been described. ${ }^{31}$ Lack of knowledge about the fundamental metabolic defect or its cellular location prevents the selection of candidate genes. No genes coding for iron binding proteins or controlling synthesis of such proteins have been located in the region telomeric to HLA-A.

Once D6S105 has been placed on a physical map linking this locus to HLA-F then an examination of markers either side of D6S105 may make it possible to predict more precisely the location of the HFE gene and initiate a search for expressed genes in the region.

We thank the Sylvia Aitken Charitable Trust for financial sup port and Dr C Darke, Welsh Regional Blood Transfusio Service, for providing samples of DNA from donors previously screened for GH. V David (I82, pMC6.7) and N Holmes (Dew3) generously provided probes.

1 Bothwell TH, Charlton RW, Motulsky AG. Hemochromatosis. In Scriver: CR, Beaudet AL, Sly WS, Valle chromatosis. In Scriver: CR, Beaudet AL, Sly WS, Valle D, eds. The metabolic basis of inherited

2 Niederau C, Fischer R, Sonnenberg A, Stremmel W, Tramp isch HJ, Strohmeyer G. Survival and causes of death in cirrhotic and in noncirrhotic patients with primary hemochromatosis. $N$ Engl f Med 1985;313:1256-62.

3 Simon M, Bourel M, Fauchet R, Genetet B. Association of HLA-A 3 and HLA-B14 antigens with idiopathic haemochromatosis. Gut 1976;17:322-4.

4 Edwards CQ, Skolnick MH, Kushner JP. Hereditary hemochromatosis: contributions of genetic analyses. Prog Hematol 1981;12:43-71.

5 Simon M, Le Mignon L, Fauchet R, et al. A study of 609 HLA haplotypes marking for the hemochromatosis gene: (1) mapping of the gene near the HLA-A locus and characters required to define a heterozygous population and (2) hypothesis concerning the underlying cause of hemochromatosis-HLA association. Am f Hum Genet 1987;41:89-105.

6 Jazwinska EC, Lee SC, Webb SI, Halliday JW, Powell LW. Localisation of the hemochromatosis gene close to D6S105. Am ₹ Hum Genet 1993;53:347-52.

7 Gasparini P, Borgato L, Piperno A, et al. Linkage analysis 
of $6 \mathrm{p} 21$ polymorphic markers and the hereditary hemochromatosis: localisation of the gene centromeric to HLAF. Hum Molec Genet 1993;2:571-6.

8 Geraghty DE, Koller BH, Hanse JA, Orr HT. The HLA class 1 gene family includes at least six genes and twelve pseudogenes and gene fragments. F Immunol 1992;149: pseudogenes

9 Stone C, Pointon JJ, Jazeinska EC, et al. Isolation of CA dinucleotide repeats close to D6S105; linkage disequilibrium with haemochromatosis. Hum Molec Gene 1994;3:2043-6.

10 Worwood M, Raha-Chowdhury R, Dorak MT, Bowen DJ, Burnett AK. Alleles at D6S265 and D6S105 define a haemochromatosis-specific genotype. Br F Haematol 1994; 86:863-6.

11 Yaouanq J, Perichon $M$, Chorney $M$, et al. Anonymous marker loci within $400 \mathrm{~kb}$ of HLA-A generate haplotype in linkage disequilibrium with the hemochromatosis (HFE). Am f Hum Genet 1994;54:252-63.

12 Powell LW, Summers KM, Board PG, Axelsen E, Webb S, Halliday JW. Expression of haemochromatosis in homozygous subjects: implications for early diagnosis and mozygous subjects: implications for early diagn
prevention. Gastroenterology 1990;98:1625-32.

13 Terasaki PI, Bernoco D, Park MS, Ozturk G, Inaki Y. Microdroplet testing for HLA-A, B, C, and D. Am $\mathcal{f}$ Clin Pathol 1978;69:103-20.

14 Worwood M, Darke C. Serum ferritin, blood donation, iron stores and haemochromatosis. Transfus Med 1993;3: 21-28.

15 Miller SA, Dykes DD, Polesky HF. A simple salting out procedure for extracting DNA from human nucleated cells. Nucleic Acids Res 1986;16:1215.

16 El Kahloun A, Jouanolle AM, Chorney M, et al. A new polymorphic probe close to HLA-A. Nucleic Acids Res 1991;19:5100

17 Chorney MJ, Sawada I, Gillespie GA, Srivastava R, Pan J, Weissman SM. Transcription analysis, physical mapping, and molecular characterization of a nonclassical humg, leukocyte antigen class I gene. Molec Cell Biol 1990;10: 243-53.

18 Worwood $M$, Raha-Chowdhury $R$, Darke C. Distribution of alleles at D6S105 and D6S265 with possible HLA haplotype associations. Tissue Antigens 1994;44:322-5.

19 Lury D, Epstein H, Holmes N. The human class I MHC gene HLA-F is expressed in lymphocytes. Int Immunol $1990 \cdot 2 \cdot 531-7$

20 Gruen JR, Goei VL, Summers KM, et al. Physical and genetic mapping of the telomeric major histocompatibility complex region in man and relevance to the primary hemochromatosis gene (HFE). Genomics 1992;14: $232-40$
21 Geraghty DE, Wei X, Orr HT, Koller BH. Human leukocyte antigen F (HLA-F). An expressed HLA gene composed of a class I coding sequence linked to a novel transcribed repetitive element. F Exp Med 1990;171:1-18.

22 Weber JL, Kwitek AE, May PE, Zoghbi HY. Dinucleotide repeat polymorphism at the D6S105 locus. Nucleic Acids Res 1991;19:968.

23 Gyapay G, Morissette J, Vignal A, et al. The 1993-94 Genethon human genetic linkage map. Nature Genet 1994; 7:246-339

24 Le Borgne-Demarquoy F, Kwiatowski TH Jr, Zoghbi HY. Two dinucleotide repeat polymorphisms at the D6S202 locus. Nucleic Acids Res 1991;19;6060.

25 Volz A, Boyle JM, Cann HM, Cottingham RW, Orr HT, Ziegler A. Report of the Second International WorkZiegler A. Report of the Second International Work-
shop on Human Chromosome 6. Genomics 1994;21 shop on

26 Lewontin RC. On measures of genetic disequilibrium. $G e$ netics 1988;120:849-52.

27 Hastbacka J, de la Chapelle A, Mahtani MM, et al. The diastrophic dysplasia gene encodes a novel sulfate transporter: positional cloning by fine-structure linkage disequilibrium mapping. Cell 1994;78:1073-87.

28 Armitage P, Berry G. Statistical methods in medical research. Oxford: Blackwell Scientific Publications, 1987.

29 Abderrahim H, Sambucy JL, Iris F, et al. Cloning the human major histocompatibility complex in YACs. Genomics 1994;23:520-7.

30 Boretto J, Jouanolle AM, Yaouang J, et al. Anonymous markers located on chromosome 6 in the HLA-A class I region: allelic distribution
Hum Genet 1992;89:33-6.

31 Conference report. International workshop on molecula genetics of haemochromatosis. $\mathcal{F}$ Med Genet 1995;32:320

32 Venditti CP, Chorney MJ. Class 1 gene contraction within the HLA-A subregion of the human MHC. Genomics 1992;14:1003-9.

33 Wei $\mathrm{H}, \mathrm{Fan}$ WF, $\mathrm{Xu} \mathrm{H}$, et al. Genes in one megabase of the HLA class I region. Proc Natl Acad Sci USA 1993;90: the HLA

34 El Kahloun A, Chauvel B, Mauvieux V. Localization of seven new genes around the HLA-A locus. Hum Molec

35 Worwood M, Dorak MT, Raha-Chowdhury R. Haplotypes in linkage disequilibrium with the hemochromatosis gene. Am f Hum Genet 1994;55:585-6.

36 Raha-Chowdhury R, Tigue NJ, Worwood M. Trinucleotide repeat microsalellite in the 5 untranslated region of HLAF. Hum Molec Genet 1994:3:2084. 